\title{
Editorial
}

\section{Long term persistence of mercury in the brain}

It is generally agreed that after mercury intoxication in which typical neurological features of "Hatter's shakes" occur, recovery is complete in the great majority of instances. Residual behavioural disturbances occur only in cases of severe intoxication and are thus rarely reported..$^{12}$ Even then, when histological changes in the brain have been carefully looked for at postmortem examination, none of any significance has been discovered, ${ }^{2}$ even in the presence of significantly increased brain mercury concentrations. Indeed, how the neurological symptoms are produced is still a mystery. Furthermore, brain mercury concentrations may occasionally be higher in apparently healthy individuals than in the general population as a whole ${ }^{34}$ without any ill effect, so far as can be seen. Where is the persisting mercury in the brain of these individuals? If it is in nerve cells is it in any particular cells and does it eventually lead to neuronal dysfunction? These questions are not often posed in relation to mercury in the brain, although they have many times been raised in relation to absorption of lead and have been hotly debated. The recent report by Hargreaves et al ${ }^{5}$ however, raises these questions anew for they detail the postmortem findings in a man who 16 years previously had had an 18 month exposure at work to metallic mercury. This individual developed typical clinical signs of neurotoxicity from which he slowly recovered over six months, and when examined postmortem 16 years later the brain was histologically normal although on analysis it did show significantly increased mercury concentrations, especially in the occipital lobes. When stained by the specific method of Danscher and Schroeder ${ }^{6}$ for mercury a large proportion of nerve cells in all brain regions showed positively staining granules that were confirmed as containing mercury by subsequent ultrastructural elemental $x$ ray analysis. It was not possible to be sure, however, that these findings were in any way related to the admittedly odd behaviour of this individual that followed recovery from poisoning, as there was a strong possibility of previous personality problems that might have been exacerbated by six months in hospital, difficulties in readjusting to the problem of finding a job, and the later development of chronic alcoholism. Unfortunately, too, no attempt had been made to assess his mental condition in detail at the time of diagnosis, so that judgment must be suspended as to whether in this case the later demonstration of mercury in the majority of neurons might have indicated that this had an adverse influence on his mental processes. In view of this impasse it might be reasonable to suggest that in future cases of mercury intoxication an attempt should be made to assess the subject's psychological state before the event and to follow this through to recovery so that a valid comparison might be made. If this type of analysis showed any deterioration from the subject's previous psychological state then it might be logical to look for ways of hastening removal of the metal ion from the tissues in subsequent cases of mercury poisoning.

What are the chances, in fact, that neuronal toxic effects were taking place during the 16 years that followed the initial 18 month period of exposure? To answer this we must look briefly into the known data, firstly, about excretion of mercury from the brain, as determined in human volunteers and in experimental animals and then into the way foreign material within nerve cells is treated, sequestered into lysosomes and in the course of time eventually expelled by exocytosis or some similar mechanism.

In man as in other animals, mercury distributes to all parts of the body on absorption, reaching a peak over one to two days. One study of the body burden in human volunteers has shown that after short exposure (14-24 minutes) the measured half time in the head is about 21 days. ${ }^{7}$ In experimental animals (rats) after a single dose the body burden diminishes in three phases, the longest with a half time of about 100 days. ${ }^{8}$ For practical reasons most other studies have been done on similarly short exposures and no chronic animal model has been developed to enable long term sequelae to be assessed, although Clarkson has emphasised that the long slow phase of excretion would play an important part in the accumulation of the metal on repeated exposure.' Moreover, the analyses of Kosta et al ${ }^{10}$ and of Rossi et al " on subjects who have long been exposed to mercury in the course of their work indicate that in fact the biological half time in the tissues should really be thought of in years rather than in months or weeks. Indeed, it is only from analyses of cases such as that of Hargreaves $e t$ 
$a l^{5}$ and the two retired mercury miners of Takahata $e t$ $a l,{ }^{2}$ that we can begin to get any real idea as to the persistence of mercury in tissues. It is clearly quite different from the order of magnitude that is generally understood from experimental work. Our current ignorance about this long term problem should be a serious cause for concern and for the development of an experimental model to learn more about the underlying processes and the risks to health. It is, it should be noted, not only the brain that is at risk here, for after long sustained exposure Kosta et al showed that the thyroid and the pituitary glands contained the highest quantities of mercury, whereas the kidney came third and the brain fifth in the hierarchy after the lungs. ${ }^{10}$ It is perhaps not so surprising, therefore, that Nylander found such high mercury concentrations in the pituitaries of three dentists with normal brain levels. ${ }^{12}$ Until we have more definite information it is not possible to dismiss the apparent non-specific clinical symptoms found and reported by Smith et $\mathrm{al}^{13}$ in workers exposed to mercury in the manufacture of chlorine, for these clearly could well be related to this long term retention of mercury in the tissues. The quoted case that initiated this discussion does not, unfortunately, help much in this matter.

What happens to mercury after it has entered the brain or indeed any other tissue? Is it likely to remain a threat to the metabolism of that tissue until expelled? What we know about the role of lysosomal dense bodies in neurons in which the mercury had apparently concentrated and their final fate is meagre, although it seems to have grown somewhat in recent years. As we have noted, mercury is sequestered in lysosomal dense bodies and the sequestering mechanism is no doubt initiated by binding of the toxic ions to proteins. We know that mercury readily does this, principally by interaction with -SH groups. ${ }^{14}{ }^{15}$ Selenium must also play a critical part, but whether immediately or later in the process is uncertain. We know from the epidemiological evidence elucidated from high mercury environments by Kosta et $a l^{10}$ and by Rossi et al ${ }^{11}$ that more selenium is retained in subjects with higher tissue levels of mercury than with lower, and in general a 1:1 molar ratio of the two elements, in all the five tissues examined, is maintained. It is possible that in the course of time selenium comes to replace sulphur, the transfer probably taking place, we might speculate, within the lysosome. In neurons as in other cells, proteins with attached mercury would probably be regarded as "abnormal" by the cell and the process of their degradation would be set in motion. This type of cell response would be similar to the events known to follow other forms of cell stress, and one important consequence would be initiation of the ubiquitin dependent pathway that catalyses cytosolic energy dependent degradation of short lived proteins; many important regulatory cell processes depend on this pathway and it appears to be central to the responses of the cell to stress. ${ }^{16-18}$ Conjugation with the polypeptide, ubiquitin, would initiate ATP dependent proteolytic break down of such proteins, but if for some reason this was not achievable then the resistant ubiquitinylated protein would be taken up into lysosomes, which is the usual fate of material taken into the cell by endocytosis. ${ }^{19}$ This may be the main route of removal of such mercury attached proteins from the cells that cannot excrete it to the body's exterior. By contrast, excretion of mercury by hair and skin cells is achieved when the cells are lost from the body. Mercury removal is facilitated in dermal appendages by the high sulphur content of proteins in these cells. Once within lysosomes in neurons and other cells some degree of enzyme degradation of the mercury bound proteins would be expected until an irreducible state is reached, which is presumably what comprises the chemically inert substance, lipofuscin. Lipofuscin tends to accumulate within nerve cells throughout life and is much more plentiful as age advances. Despite this there is also evidence suggesting that nerve cells can discharge dense bodies which are then taken up into astrocytes and passed to the vascular endothelial cells to be ultimately expelled into the blood stream. ${ }^{20}$ If so then this is a slow process and the safety of the nerve cell from its contained mercury will depend on the stability of the dense bodies and, should the cell die, the chemical inertness of its contained residual proteins. Whether neurons are especially slow in discharging dense bodies is not certain but as noted earlier Nylander observed that pituitary glands sampled postmortem from dentists contained excessive amounts of mercury, much more than was present in their brain tissue. ${ }^{12}$ Similarly Kosta et al also found remarkably high concentrations in this gland and in the thyroid in Yugoslav miners of the order a thousand times the amounts found in an unexposed population. ${ }^{10}$ The experimental studies of ThorlaciusUssing et al tend to confirm this for the pituitary. ${ }^{21}$ Surprisingly, this has not been followed up, but there is no reason to believe that this is due to anything other than the slow release of lysomal dense bodies from cells, although further work may place more specificity on this tissue selectivity. Moreover, there is no reason for believing that the functions of these two endocrine glands are in any way prejudiced by the high concentrations found in them, and by the same token we may believe that the neurons too may not be significantly embarrassed by the mercury that resides in their dense bodies. If this belief is true this is a remarkable tribute to the efficacy of this cellular defence mechanism.

J B CAVANAGH

MRC Toxicology Unit,

MRC Laboratories,

Woodmansterne Road, Carshalton, Surrey SM5 4EF. 


\section{References}

1 Teleky L. Gewerbliche Vergiftungen. Berlin: Springer-Verlag, 1955.

2 Takahata N, Hayashi H, Watanabe B, Anso T. Accumulation of mercury in brains of two autopsy cases with chronic inorganic mercury poisoning. Folia Psychiatrica \& Neurologica Japonica 1970;24:59-69.

3 Mottet NK, Body RL. Mercury burden of human autopsy organs and tissues: flameless atomic absorption spectroscopy. Arch Environ Health 1974;29:18-24.

4 Yukawa M, Suzuki-Yasumoto M, Amano K, Terai M. Distribution of trace elements in the human body determined by neutron activation analysis. Arch Environ Health 1980;35:36-44.

5 Hargreaves RJ, Evans JG, Janota I, Magos L, Cavanagh JB. Persistent mercury in nerve cells 16 years after metallic mercury poisoning. Neuropathol Appl Neurobiol (in press).

6 Danscher G, Schroeder HD. Histochemical demonstration of mercury induced changes in rat neurons. Histochemistry 1979;60:1-7.

7 Hursh JB, Cherian MG, Clarkson TW, Vostal JJ, Mallie RV. Clearance of mercury $(\mathrm{Hg}-197, \mathrm{Hg}-203)$ vapor inhaled by human subjects. Arch Environ Health 1976;1:302-9.

8 Rothstein AC, Hayes AD. The metabolism of mercury in the rat studied by isotope techniques. J Pharmacol Exper Ther 1960;130:166-76.

9 Clarkson TW. The pharmacology of mercury compounds. Annual Reviews of Pharmacology 1972:12:375-406.

10 Kosta L, Byrne AR, Zelenko V. Correlation between selenium and mercury in man following exposure to inorganic mercury. Nature (London) 1975;254:238-9.
11 Rossi LC, Clemente GF, Santaroni G. Mercury and selenium distribution in a defined area and its population. Arch Environ Health 1976:31:160-5.

12 Nylander M. Mercury in pituitary glands of dentists. Lancet 1986;i:442.

13 Smith R, Yorwald A, Fatil L, Mooney T. Effects of exposure to mercury in the manufacture of chlorine. Am Ind Hyg Assoc 1970;31:687-93.

14 Webb JL. Enzyme and metabolic inhibitors. Vol II. New York: Academic Press, 1966:760 et seq.

15 Fang SC, Fallin E. The binding of various mercurial compounds to serum proteins. Bull Environ Contam Toxicol 1976;15:110-7.

16 Hershko A. Ubiquitin: roles in protein modification and breakdown. Cell 1983;34:11-2.

17 Hershko A, Ciechanover A. The ubiquitin pathway for the degradation of intracellular proteins. Prog Nucleic Acid Res Mol Biol 1986;33:19-56.

18 Finlay D, Varshavsky $A$. The ubiquitin system: functions and mechanism. Trends in Biochemical Science 1985:343-7.

19 Goldberg AL, St John AC. Intracellular protein degradation in mammalian and bacterial cells. Annu Rev Biochem 1976;45: 747-803.

20 Wolf JR. The development of intracellular blood vessels interacts with astrocyte development and neuron positioning in the rat neocortex. In: Wolf JR, Sievers J, Berry M, eds. Mesenchymalepithelial interactions in neural development. Berlin: SpringerVerlag, 399-412.

21 Thorlacius-Ussing O, Møller-Madsen B, Danscher G. Intracellular accumulation of mercury in the anterior pituitary of rats exposed to mercuric chloride. Exp Mol Pathol 1985;42:278-86.

\section{Destruction of manuscripts}

From 1 July 1985 articles submitted for publication will not be returned. Authors whose papers are rejected will be advised of the decision and the manuscripts will be kept under security for three months to deal with any inquiries and then destroyed. 